\title{
INTEGRATIVE VIEW OF THE MECHANISMS THAT INDUCE ACUTE KIDNEY INJURY AND ITS TRANSITION TO CHRONIC KIDNEY DISEASE
}

\author{
LUis Enrique García-Ortuño ${ }^{1,2}$ and Norma Araceli Bobadilla ${ }^{1 *}$
}

${ }^{1}$ Molecular Physiology Unit, Instituto de Investigaciones Biomédicas, Universidad Nacional Autónoma de México, and Department of Nephrology and Mineral Metabolism, Instituto Nacional de Ciencias Médicas y Nutrición Salvador Zubirán; ${ }^{2}$ Department of Pathology, Facultad de Medicina Veterinaria y Zootecnia, Universidad Nacional Autónoma de México. Mexico City, Mexico

\begin{abstract}
There is ample evidence showing that acute kidney injury (AKI) increases the risk of developing chronic kidney disease (CKD). Although considerable efforts have been undertaken in recent years to elucidate the mechanisms responsible for the AKI to CKD transition, many questions remain to be answered. In this review, we address most of the latest studies elucidating the mechanisms involved in this transition. Based on recent studies, the consensus to date is that endothelial and proximal tubular epithelium injury along with the activation of inflammatory processes occurring after an AKI episode, not only establish a close interrelation but also trigger a series of signaling pathways that culminate in the generation of tubulointerstitial fibrosis and chronic hypoxia, which lead to the progressive deterioration of functional tissue. These events highlight that the tubular epithelium does not appear to be the same after cell damage occurs. In this review, we present the advances aimed at elucidating the mechanisms that lead to a maladaptive response and how sex hormones seem to be involved in a positive or negative adaptive response. Elucidating and characterizing the mechanisms responsible for the AKI to CKD transition are an indispensable preliminary step that will help to identify the most important actors in this process. (REV INVEST CLIN. 2018;70:261-8)
\end{abstract}

Key words: Renal fibrosis. Hypoxia. Inflammation. Oxidative stress. Maladaptive repair. Tubular cells.

Corresponding author:

*Norma Araceli Bobadilla

Unidad de Fisiología Molecular

Instituto Nacional de Ciencias Médicas

y Nutrición Salvador Zubirán

Vasco de Quiroga, 15

Col. Belisario Domínguez, Del. Tlalpan

C.P.14080, México City, México

E-mail: nab@biomedicas.unam.mx

Received for publication: 26-03-2018

Approved for publication: 03-07-2018

doi: $10.24875 / R I C .18002546$ 


\section{ACUTE KIDNEY INJURY (AKI)}

$\mathrm{AKI}$ is generally defined as a clinical syndrome caused by an abrupt reduction in renal blood flow that culminates in the decrease of urine production and the accumulation of toxic compounds. These alterations are observed within several hours or days once the event has occurred ${ }^{1-3}$. AKI is a serious public health problem with high morbidity and mortality, associated with an increased long-term risk of developing chronic kidney disease (CKD) ${ }^{4}$. Moreover, this condition generates an additional cost to health systems and longer hospital stays $s^{5,6}$. Unfortunately, the interventions to prevent AKI or to improve prognosis have not been efficient enough. Another difficult issue that clinicians around the world face is the definition and classification of AKI, limiting its precise diagnosis. The current classification is included in the Clinical Practice Guidelines for Kidney Disease: Improving Global Outcomes (KDI$\mathrm{GO}$ ), which maintained the definition and staging of AKI based on the previous criteria of risk, injury, failure, loss, end-stage renal disease (ESRD), and AKI network. This new classification considers the elevation of creatinine $\geq 0.3 \mathrm{mg} / \mathrm{dL}$ in $48 \mathrm{~h}$, or a greater increase of $\geq 1.5$ times of the basal values in the past 7 days, or decrease in the urinary output to $<0.5 \mathrm{~mL} / \mathrm{kg} / \mathrm{h}$ during $6 \mathrm{~h}$, categorizing the episodes in three stages in relation to the severity of the renal damage (KDIGO 1,2 , or 3$)^{3}$.

Despite these barriers to diagnosis, it has been estimated that $\mathrm{AKI}$ occurs in $\mathbf{1 3 . 3}$ million people each year worldwide, $85 \%$ of whom live in countries with medium or low income, and the disease contributes to approximately 1.7 million deaths yearly. In a recently published meta-analysis that included 700 million hospitalized patients, $21 \%$ were found to have suffered from an $\mathrm{AKI}$ episode ${ }^{5-7}$. It is important to consider that $\mathrm{AKI}$ incidence is substantially higher in critically ill patients on the intensive care unit, i.e., $30-70 \%$. In a study that included 49 million patients, it was observed that AKI occurred in one of five adults and one of every three hospitalized children ${ }^{5,8}$. Similarly, AKI etiology may vary depending on geographic region and socioeconomic conditions ${ }^{5,9}$, but the most frequent causes of $\mathrm{AKI}$ are associated with generalized or localized ischemic damage due to surgeries, sepsis, trauma, infections, dehydration, and toxic drug damage $^{4}$. In particular, several widely used agents, such as radiocontrast media or nonsteroidal anti-inflammatory drugs, can cause direct renal tissue damage, ischemic injury, or both.

\section{Vascular endothelium in the $\mathrm{AKI}$}

The kidney has one of the most abundant populations of endothelial cells compared with other organs ${ }^{10,11}$. The energy demand in this organ is high, and the partial pressure of oxygen is relatively low with fluctuating values between 40 and $60 \mathrm{mmHg}$ in the cortex and 10 and $20 \mathrm{mmHg}$ in the renal medulla ${ }^{12}$. Therefore, the vascular architecture is highly susceptible to blood perfusion and oxygenation ${ }^{4,13}$.Endothelial cells physiologically contribute to the maintenance of vascular tone, regulation of blood flow, and vascular permeability ${ }^{14}$. Vascular endothelial growth factor (VEGF) is required for the maintenance of the peritubular capillaries' homeostasis. VEGF is expressed in podocytes, proximal tubule, and thick ascending loop, while the VEGF receptors 1 and 2 are located in endothelial cells, and peritubular and glomerular capillaries ${ }^{15,16}$. AKI is accompanied by endothelium cell damage, which is characterized by the alteration of the actin cytoskeleton, causing the detachment of endothelial monolayer cells and affecting the tight intercellular junctions which, in turn, increase vascular permeability and the production of edema. Microvascular damage induces endothelial activation together with the expression of cell surface markers, such as intercellular adhesion molecules, which promote adhesion and recruitment of leukocytes and platelets ${ }^{4}$. The arterioles, particularly in the post-ischemic area, undergo intense vasoconstriction in response to an increase in tissue concentrations of endothelin, angiotensin II, thromboxane $A 2$, prostaglandin $H 2$, leukotrienes $\mathrm{C} 4$ and $\mathrm{D} 4$, and adenosine (Fig. 1). In addition, vasodilatation is limited in response to decreased acetylcholine, bradykinin, nitric oxide, and other vasodilator molecules ${ }^{17}$. The imbalance in the vasoactive release contributes to the decrease in renal blood flow and the maintenance of renal hypoperfusion after several hours.

\section{Tubular epithelium in AKI}

Once the hypoxic state occurs, tubular epithelial cells are unable to maintain adequate levels of adenosine triphosphate (ATP); therefore, they suffer damage and death, primarily by necrosis and apoptosis ${ }^{17-19}$. 
Figure 1. Integration of the mechanisms involved in acute kidney injury.

$\Delta$ Pro-inflammatory factors produced by the epithelium: tumor necrosis factor (TNF)- $\alpha$, interleukin (IL)-1, IL-6, CXCL8, MCP-1, CCL5, and ENA 78.

+ Pro-inflammatory factors produced by inflammatory cells: TNF- $\alpha, \mathrm{IL}-1, \mathrm{CXCL} 8, \mathrm{MCP}-1$, and eicosanoids.

Endothelial adhesion molecules: intercellular adhesion molecules, $\mathrm{P}$ and $\mathrm{E}$ selectins.

Tight junctions.

Adhesion molecules ( $\beta$-integrin).

$\mathrm{Na}+/ \mathrm{K}+$-ATPase. $\mathrm{M} 1$ : type 1 macrophages.

\section{Normal Epithelium}

Injured Epithelium

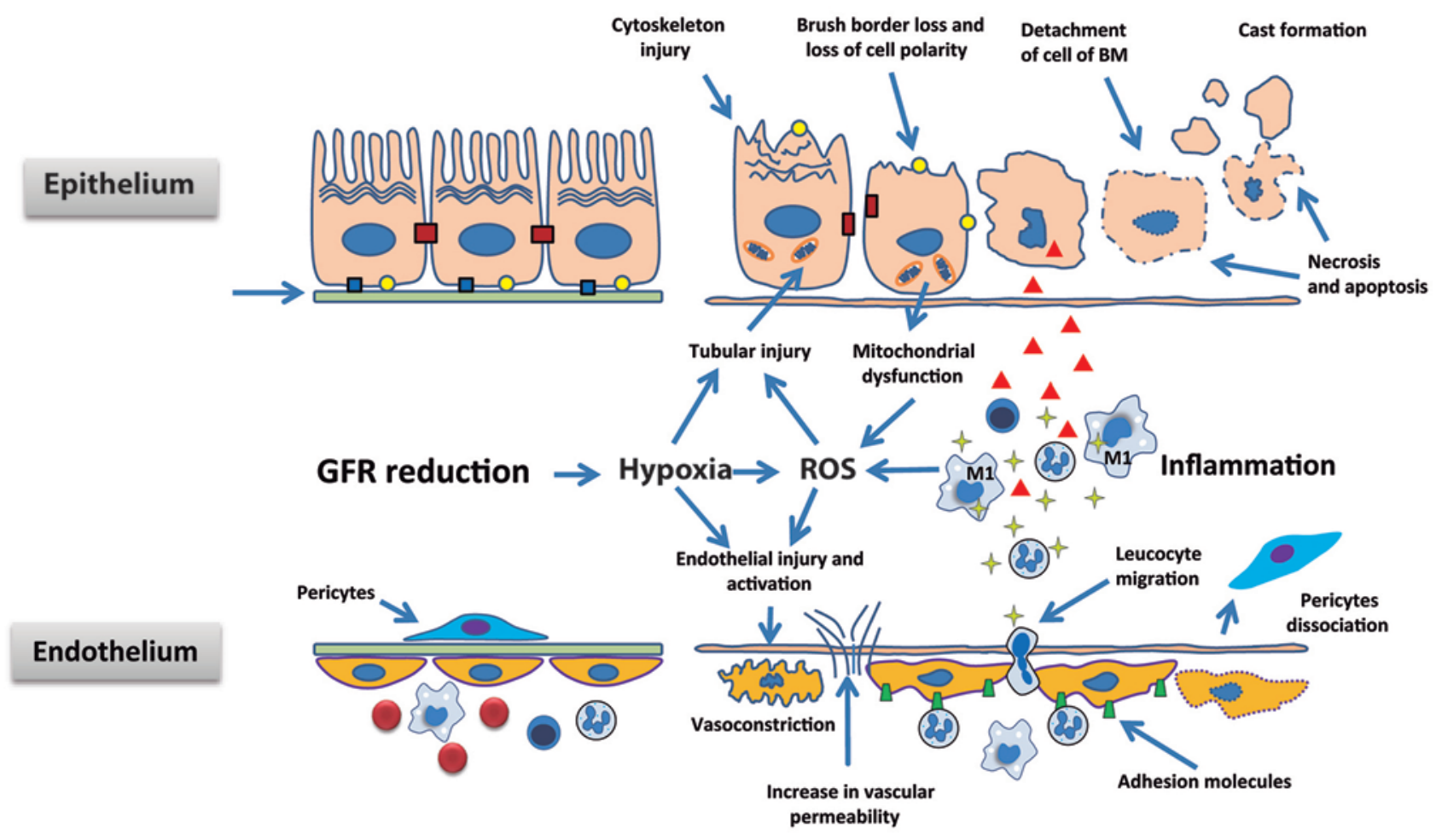

The proximal tubular epithelium is particularly more sensitive to hypoxic states than the rest of the tubular segments because it has a higher energy metabolic demand and a limited capacity for anaerobic glycolysis. It is well-known that the cytoskeleton has an integral role in cell function and structure through maintaining polarity, endocytosis, signal transduction, motility, organelle movement, exocytosis, cell division, and cell-matrix adhesion. Therefore, the damage to the tubular cytoskeleton has diverse effects on cellular function ${ }^{14}$. The ATP reduction also leads to the loss of the brush border of the proximal tubule, change in cell polarity, and alteration in the location of adhesion molecules and membrane proteins such as the $\mathrm{Na}^{+} \mathrm{K}^{+}$ATPase pump and $\beta$-integrins. The relocation of the $\beta$-integrins and the lack of adhesion of the epithelial cells results in the exfoliation of these cells into the tubular lumen. The cellular debris combined with the Tamm-Horsfall protein and fibronectin promotes the distinctive cast formation in this disease, which may obstruct the tubules and later increase the intratubular pressure (Fig. 1) ${ }^{17}$.

\section{Inflammatory process in AKI}

During $\mathrm{AKI}$, an inflammatory cascade is initiated, where chemokines are the main mediators of inflammation, promoting the expression of adhesion molecules, and the activation and infiltration of leukocytes $^{20}$. This inflammatory response involves cells of 
the immune system such as neutrophils, monocytes/ macrophages, dendritic cells, and natural killer lymphocytes $^{21,22}$. Initially, the inflammatory process is characterized by the marginalization of the leukocytes to the activated vascular endothelium. Subsequently, there is a transmigration of the leukocytes to the inflammatory site ${ }^{14}$. Neutrophils and monocytes regulate the inflammatory process in the acute phase within the first $24 \mathrm{~h}^{4}$. The renal tubular epithelium also contributes to the exacerbation of the inflammatory process, since it synthesizes proinflammatory and chemoattractant molecules (Fig. 1). Several studies have shown that the prevention of the inflammatory process through the inhibition of neutrophils and monocytes/macrophages or by blocking endothelial cell-leukocyte interactions has a renoprotective effect ${ }^{23,24}$. T-lymphocytes are also involved in the development and maintenance of AKI. Accordingly, nude mice that are deficient in T-cells are protected from ischemia/reperfusion injury. Further studies, however, are warranted to elucidate in greater detail the participation and interaction of inflammatory cells with the resident neighboring immune cells 22 .

\section{Oxidative stress in AKI}

Oxidative stress is also involved in the pathophysiology of both $A K I$ and $C K D^{25-27}$, since it can affect renal hemodynamics by reducing the vasodilatory capacity of nitric oxide or by injuring the endothelial cells. Likewise, oxidative stress can also induce tubular epithelial damage by promoting cell death by apoptosis or necrosis ${ }^{26}$. The superoxide anion is the primary reactive oxygen species (ROS) that participates in injuring the kidney. There are also antioxidants that serve to protect the cellular integrity induced by ROS ${ }^{25,26}$. It is widely known that during renal injury, the intracellular antioxidants are reduced contributing to exacerbate the renal injury ${ }^{25}$. Particularly, the proximal tubular cells have abundant mitochondria; therefore, these cells are highly vulnerable to damage by the oxidative stress generated by hypoxia ${ }^{28}$. This organelle normally produces small amounts of ROS ${ }^{29}$. Under pathological conditions, the decoupling of oxidative phosphorylation and the loss to the integrity of the mitochondrial membrane induce an excessive amount of ROS coming from the respiratory chain, particularly complex I and III (Fig. 1). Mitochondrial dysregulation is also characterized by a decrease in cellular respiration and by a lower production of ATP as well as by the release of proapoptotic factors 25 . Another frequent source of ROS in AKI corresponds to the infiltration of inflammatory cells, primarily neutrophils, and macrophages that, in addition to releasing a large number of pro-inflammatory cytokines, suffer the so-called respiratory burst, generating free radicals (Fig. 1) 26,27,30.

\section{MECHANISMS INVOLVED IN THE TRANSITION OF AKI TO CKD}

Several years ago, it was thought that patients who survived an episode of $A K I$ and who had a recovery of renal function would not have long-term consequenc$\mathrm{es}^{31}$. However, in recent years, this concept has changed based on several experimental and epidemiological studies demonstrating that $A K I$ is a risk factor, leading to progressive kidney disease ${ }^{7,32-44}$. In a recent meta-analysis that included 13 previously reported studies in patients who survived an AKI episode, the incidence of CKD and ESRD was $25.8 \%$ and $8.6 \%$, respectively ${ }^{34,35}$. In addition, it has been reported that patients with greater AKI severity have a higher risk of a more rapid progression to $C K D^{36-38}$. In older adults, the risk of ESRD after an AKI episode increases from 2 to 13 times $^{45}$. However, in another study carried out in 126 children who presented with AKI without any other condition, $10 \%$ developed CKD in a period between 1 and 3 years ${ }^{46}$.

The AKI to CKD transition has attracted the attention of several researchers, including those in our group, who have attempted to elucidate the mechanisms responsible for this transition. After an AKI episode, a complete repair of the function and renal structure, known as an adaptive response, would be expected; however, in most cases, this repair does not occur, since the repair seems to be incomplete or defective, known as a maladaptive response $e^{4,47-49}$. The working group of the $13^{\text {th }}$ conference of the acute dialysis quality initiative has defined adaptive repair as the resolution of renal structure and function without long-term sequelae in a period of 90 days. Conversely, maladaptive repair was defined as a process that results from structural damage, such as renal fibrosis, and with consequent progressive reduction of renal function ${ }^{49}$. 
Figure 2. Integration of the mechanisms involved in the acute kidney injury to chronic kidney disease transition.

- Profibrotic factors produced by the epithelium: transforming growth factor (TGF)- $\beta 1$ and connective tissue growth factor.

+ Profibrotic factors produced by inflammatory cells: TGF- $\beta$, platelet-derived growth factor-B, and fibroblast growth factor-2. $\sim$ Extracellular matrix: fibronectin and collagen. M2: type 2 macrophages.

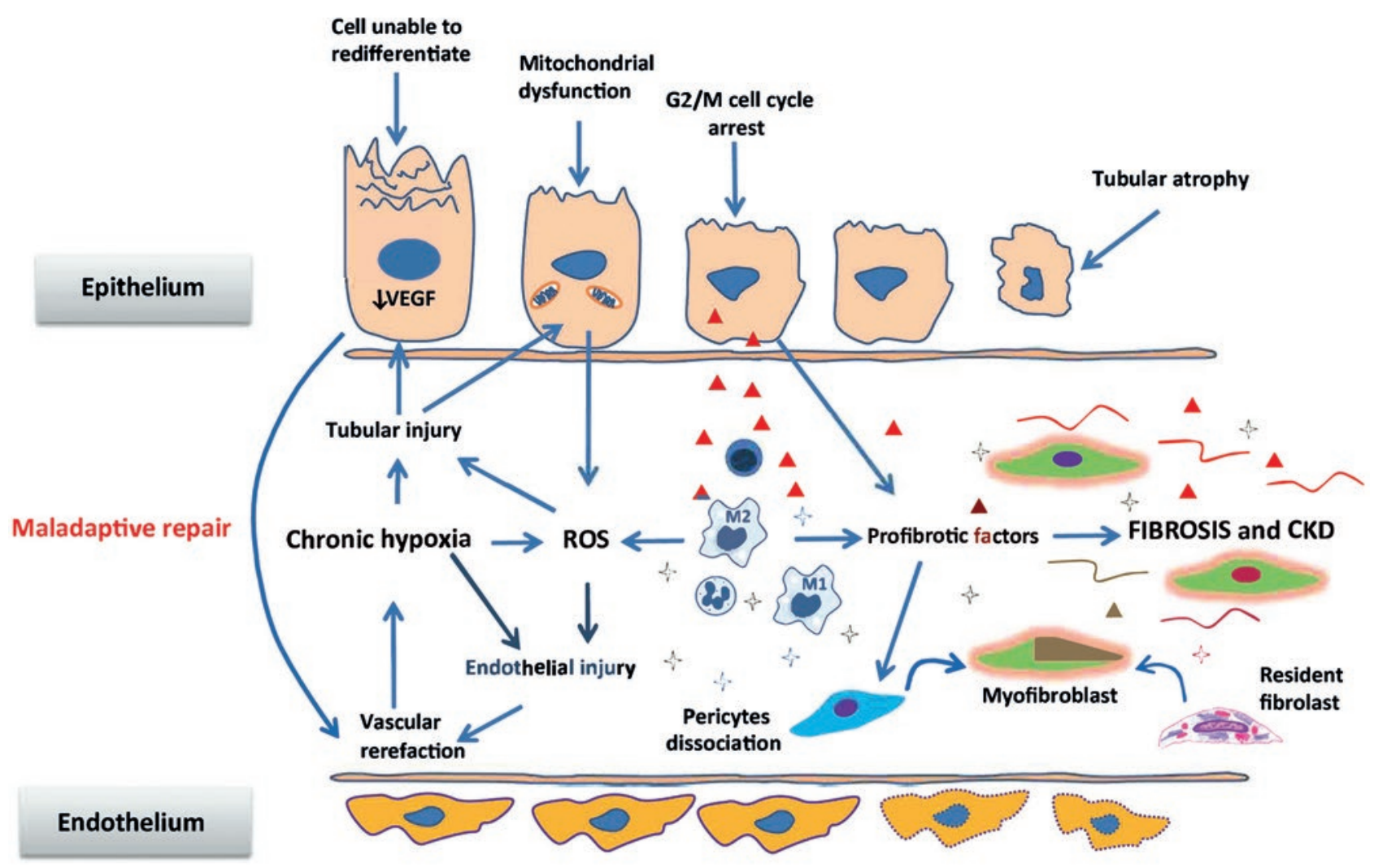

Several studies have shown that one hallmark of maladaptive repair is the persistence of the inflammatory process, proliferation of fibroblasts, and excessive deposition of extracellular matrix $43,44,50-56$. Therefore, the understanding of the mechanisms involved in the AKI to CKD transition will undoubtedly have an impact on the subsequent management of patients who suffered AKI.

\section{Tubular epithelium in the transition of $A K I$ to CKD}

The renal tubular epithelium plays a central role in the fibrotic response that leads to progressive CKD ${ }^{49,57-59}$. The mechanism by which tubular cells promote renal fibrosis is complex; however, it has been described as a maladaptive repair because the epithelial cells lose the ability to redifferentiate and recover their normal structure; therefore, there is a pathological arrest in the $\mathrm{G} 2 / \mathrm{M}$ phase of the cell cycle (Fig. 2) ${ }^{54}$. These abnormal epithelial cells have an intense signaling activity and express cytokines and profibrotic peptides that promote interstitial infiltration with inflammatory cells and the proliferation of fibroblasts ${ }^{54,57,60}$. The arrested cells in G2/M synthesize profibrotic factors: transforming growth factor (TGF)- $\beta 1$ and connective tissue growth factor (CTGF) ${ }^{49,54}$. The specific and isolated lesion of the proximal tubule is sufficient to induce the activation of the inflammatory response, vascular rarefaction, and renal fibrosis ${ }^{60,61}$.

\section{Vasculature in the AKI to CKD transition}

Basile et al. ${ }^{62}$, Babickova et al. ${ }^{63}$, and Hörbelt et al. ${ }^{64}$ have shown that capillary density is reduced up to $45 \%, 4$ weeks after inducing AKI in murine models. This finding indicates that unlike the tubular 
epithelium, the vascular epithelium has less regeneration potential ${ }^{10}$. The absence of vascular repair is due to the reduction in the expression of VEGF ${ }^{12,60,63}$. In fact, it has been shown that administration of VEGF after ischemia preserves capillary density in the rat ${ }^{65}$. Vascular rarefaction may be a key element in the development of fibrosis, since it maintains renal tissue in a chronic hypoxic state, which initiates the activation of hypoxia-induced signaling pathways. Accordingly, the reduction of renal capillary density correlates with the severity of fibrosis ${ }^{62}$.

Chronic renal hypoxia has been considered a therapeutic target for the AKI to CKD transition ${ }^{12,66}$. Hypoxia also has other deleterious effects, since it is the cause of apoptosis in renal epithelial cells and may activate local fibroblasts that contribute to fibrogenesis $^{62}$. Renal fibrosis aggravates hypoxia, further reducing the efficiency of oxygen diffusion by increasing the distance between capillaries and tubules ${ }^{59}$. In addition, in vitro studies have linked hypoxia to the inflammatory process because it induces leukocyte adhesion to the endothelium through the activation of $\beta 2$ integrin ${ }^{67}$. It is not entirely clear how vascular rarefaction and chronic hypoxia persist because hypoxiainducible factor (HIF) must be activated and initiates the induction of multiple angiogenic factors to stimulate a vascular compensatory response; however, this mechanism is not well activated and almost always is not sufficient to avoid vascular rarefaction ${ }^{15}$.

\section{Origin of cells that induce fibrosis (myofibroblasts)}

The origin of myofibroblasts is under debate and has stimulated intense research in this field $13,49,53,60,62,68$. Several studies have reported that pericytes are the primary cells that contribute to the accumulation of myofibroblasts through the transdifferentiation of pericyte-myofibroblast ${ }^{69-72}$. Pericytes are specialized cells that are attached to endothelial cells and maintain vascular stability and integrity. The loss of pericytes of the vascular endothelium together with its participation in renal fibrosis causes instability in the capillaries, thereby contributing to vascular rarefaction $^{13}$. It has also been reported that this process is accompanied by the upregulation of platelet-derived growth factor receptor (PDGFR)- $\beta$ and PDGFR- $\alpha$, while pharmacological blockade of these receptors prevents the dissociation of pericytes ${ }^{69}$. The vascular stability is also reduced after renal damage by alterations in the regulation of the tissue inhibitor of metalloproteinases 3 and disintegrin, and metalloproteinase with thrombospondin motifs 1 , which are genes that regulate proteolysis and angiogenesis in the pericyte ${ }^{73,74}$. Other cells that could be involved in the origin of myofibroblasts are resident fibroblasts, cells derived from the bone marrow, endothelial cells, and erythropoietin-producing cells ${ }^{75}$. It has been suggested that myofibroblasts may also have their origin derived from the damaged tubular epithelium, due to the process of epithelial-mesenchymal transdifferentiation; however, several studies question this statement ${ }^{70,75}$.

\section{Inflammatory process in the AKI to CKD transition}

Macrophages, in particular, play a central role in both the injured cells and in the repair of the affected tissue $^{4}$. The sustained infiltration of macrophages can induce fibrosis and progression to CKD by generating profibrotic cytokines including TGF- $\beta$, PDGF-B, and fibroblast growth factor 2 , which promote proliferation and survival of myofibroblasts. After AKI, the presence of two subtypes of macrophages that may differentiate under the influence of the localmicroenvironment has been demonstrated 22,76 . Type 1 (M1) macrophages (induced by interferon and lipopolysaccharides) migrate immediately after renal injury and are responsible for the production of pro-inflammatory molecules, while macrophages Type 2 (M2) (stimulated by interleukin [IL]-4 and IL-13) arise in the recovery phase of $\mathrm{AKI}$ and synthesize factors that help in the proliferation of tubular cells and the repair of renal damage ${ }^{76}$.

\section{Sexual dimorphism in the AKI to CKD transition}

A rarely investigated aspect in the pathophysiological course, clinical presentation, and prognosis of kidney disease is the marked differences that exist between men and women. Several studies in different renal pathologies have shown that men are more susceptible than women ${ }^{77}$; however, the mechanisms have not been fully elucidated. Our laboratory has been interested in this phenomenon, particularly in what occurs in the AKI to CKD transition, considering that by deepening the mechanisms of renoprotection in females or susceptibility in males, new therapeutic 
targets might be identified. Female and male rats underwent a period of bilateral renal ischemia for $45 \mathrm{~min}$ and were evaluated after $24 \mathrm{~h}, 1,2,3$, and 4 months after ischemia. In addition, oophorectomized rats were also used. As we previously reported ${ }^{43,55,78}$, male rats experienced the AKI to CKD transition 4 months after renal ischemia, unlike female rats that did not have this transition. The mechanisms of renoprotection in female rats were associated to an increase in antioxidant enzymes and, therefore, less oxidative damage. Moreover, it was observed that the female rats had a significant increase in mRNA levels of eNOS, TGF- $\beta$, and HIF- $1 \alpha$. A particularly interesting finding was the fact that female oophorectomized rats behaved similarly to male rats; in other words, this group developed $C K D^{44}$. These results strongly suggest the participation of sex hormones in the transition from AKI to CKD.

In summary, the growing evidence in the close relationship and dependence between AKI and CKD has stimulated the interest of several research groups that have made important contributions to the body of knowledge regarding the mechanisms that bridge these two pathologies. However, given the great complexity, the different cell types and the diversity of factors involved, there are still many questions to answer.

\section{ACKNOWLEDGMENTS}

Studies in the authors' laboratory cited in the review were supported by grants from the Mexican Council of Science and Technology (CONACyT) (235855, 235964 , and 272390 to $N A B$ ) and from the National University of Mexico (IN223915 to NAB). This review was performed in partial fulfillment of the requirements for the PhD degree of Luis Enrique García-Ortuño, who is a doctoral student from Programa de Doctorado en Ciencias Biomédicas, Universidad Nacional Autónoma de México (UNAM) and received a fellowship from Dirección General de Asuntos del Personal Académico UNAM.

\section{REFERENCES}

1. Takaori K, Yanagita M. Insights into the mechanisms of the acute kidney injury-to-chronic kidney disease continuum. Nephron. 2016;134:172-6.
2. Bellomo R, Kellum JA, Ronco C. Acute kidney injury. Lancet. 2012;380:756-66.

3. Kellum JA, Lameire N, Group KA. Diagnosis, evaluation, and management of acute kidney injury: a KDIGO summary (Part 1). Crit Care. 4;17:204.

4. Zuk A, Bonventre JV. Acute kidney injury. Annu Rev Med. 2016;67:293-307.

5. Lameire NH, Bagga A, Cruz D, et al. Acute kidney injury: an increasing global concern. Lancet. 2013;382:170-9.

6. Rewa O, Bagshaw SM. Acute kidney injury-epidemiology, outcomes and economics. Nat Rev Nephrol. 2014;10:193-207.

7. Lewington AJ, Cerdá J, Mehta RL. Raising awareness of acute kidney injury: a global perspective of a silent killer. Kidney Int .2013;84:457-67.

8. Susantitaphong P, Cruz DN, Cerda J, et al. World incidence of AKI: a meta-analysis. Clin J Am Soc Nephrol. 2013;8:1482-93.

9. Feehally J. The ISN 0by 25 global snapshot study. Ann Nutr Metab. 2016;68 Suppl 2:29-31.

10. Maringer K, Sims-Lucas S. The multifaceted role of the renal microvasculature during acute kidney injury. Pediatr Nephrol. 2016:31:1231-40.

11. Verma SK, Molitoris BA. Renal endothelial injury and microvascular dysfunction in acute kidney injury. Semin Nephrol. 2015;35:96-107.

12. Tanaka S, Tanaka T, Nangaku M. Hypoxia as a key player in the AKI-to-CKD transition. Am J Physiol Renal Physiol. 2014;307:F1187-95.

13. Ferenbach DA, Bonventre JV. Mechanisms of maladaptive repair after AKI leading to accelerated kidney ageing and CKD. Nat Rev Nephrol. 2015;11:264-76.

14. Sharfuddin AA, Molitoris BA. Pathophysiology of ischemic acute kidney injury. Nat Rev Nephrol. 2011;7:189-200.

15. Tanaka S, Tanaka T, Nangaku M. Hypoxia and dysregulated angiogenesis in kidney disease. Kidney Dis (Basel). 2015;1:80-9.

16. Dimke H, Sparks MA, Thomson BR, Frische S, Coffman TM Quaggin SE. Tubulovascular cross-talk by vascular endothelial growth factor a maintains peritubular microvasculature in kidney. J Am Soc Nephrol. 2015;26:1027-38.

17. Bonventre JV, Yang L. Cellular pathophysiology of ischemic acute kidney injury. J Clin Invest. 2011;121:4210-21.

18. Bonventre JV. Pathophysiology of AKI: injury and normal and abnormal repair. Contrib Nephrol. 2010;165:9-17.

19. Sancho-Martínez SM, López-Novoa JM, López-Hernández FJ. Pathophysiological role of different tubular epithelial cell death modes in acute kidney injury. Clin Kidney J. 2015;8:548-59.

20. Malek $M$, Nematbakhsh $M$. Renal ischemia/reperfusion injury; from pathophysiology to treatment. J Renal Inj Prev. 2015;4:20-7.

21. Tögel F, Westenfelder $C$. Recent advances in the understanding of acute kidney injury. F1000Prime Rep 2014:6.83.

22. Lee SA, Noel S, Sadasivam M, Hamad AR, Rabb H. Role of immune cells in acute kidney injury and repair. Nephron. 2017; 137:282-6

23. Kinsey GR, Li L, Okusa MD. Inflammation in acute kidney injury. Nephron Exp Nephrol. 2008;109:e102-7.

24. Ratliff BB, Rabadi MM, Vasko R, Yasuda K, Goligorsky MS. Messengers without borders: mediators of systemic inflammatory response in AKI. J Am Soc Nephrol. 2013;24:529-36.

25. Okamura DM, Pennathur S. The balance of powers: redox regulation of fibrogenic pathways in kidney injury. Redox Biol. 2015; 6:495-504.

26. Ratliff BB, Abdulmahdi W, Pawar R, Wolin MS. Oxidant mechanisms in renal injury and disease. Antioxid Redox Signal. 2016 25:119-46.

27. Sureshbabu A, Ryter SW, Choi ME. Oxidative stress and autophagy: crucial modulators of kidney injury. Redox Biol. 2015; 4:208-14.

28. Gorin Y. The kidney: an organ in the front line of oxidative stress-associated pathologies. Antioxid Redox Signal. 2016; 25:639-41.

29. Agarwal A, Dong Z, Harris R, et al. Cellular and molecular mechanisms of AKI. J Am Soc Nephrol. 2016;27:1288-99.

30. Bonventre JV, Zuk A. Ischemic acute renal failure: an inflammatory disease? Kidney Int. 2004;66:480-5.

31. Pannu N. Bidirectional relationships between acute kidney injury and chronic kidney disease. Curr Opin Nephrol Hypertens. 2013; 22:351-6

32. Frossard JL, Quadri R, Hadengue A, Morel P, Pastor CM. Endothelial nitric oxide synthase regulation is altered in pancreas from cirrhotic rats. World J Gastroenterol. 2006;12:228-33.

33. Coca SG, Yusuf B, Shlipak MG, Garg AX, Parikh CR. Long-term risk of mortality and other adverse outcomes after acute kidney 
injury: a systematic review and meta-analysis. Am J Kidney Dis. 2009:53:961-73

34. Coca SG, Singanamala S, Parikh CR. Chronic kidney disease after acute kidney injury: a systematic review and meta-analysis. Kidney Int. 2012;81:442-8

35. Sanches TR, Volpini RA, Massola Shimizu MH, et al. Sildenafil reduces polyuria in rats with lithium-induced NDI. Am J Physiol Renal Physiol. 2012;302:F216-25.

36. Chawla LS, Amdur RL, Amodeo S, Kimmel PL, Palant CE. The severity of acute kidney injury predicts progression to chronic kidney disease. Kidney Int. 2011;79:1361-9.

37. Rifkin DE, Coca SG, Kalantar-Zadeh K. Does AKI truly lead to CKD? J Am Soc Nephrol. 2012;23:979-84.

38. Akcay A, Nguyen Q, Edelstein CL. Mediators of inflammation in acute kidney injury. Mediators Inflamm. 2009;2009:137072.

39. Chawla LS, Kimmel PL. Acute kidney injury and chronic kidney disease: an integrated clinical syndrome. Kidney Int. 2012; 82:516-24.

40. Moll S, Ebeling M, Weibel F, Farina A, et al. Epithelial cells as active player in fibrosis: findings from an in vitro model. PLOS One. 2013;8:e56575.

41. Leung KC, Tonelli M, James MT. Chronic kidney disease following acute kidney injury-risk and outcomes. Nat Rev Nephrol. 2013; 9:77-85.

42. Takaori K, Nakamura J, Yamamoto S, et al. Severity and frequency of proximal tubule injury determines renal prognosis. J Am Soc Nephrol. 2016;27:2393-406.

43. Rodríguez-Romo R, Benítez K, Barrera-Chimal J, et al. AT1 receptor antagonism before ischemia prevents the transition of acute kidney injury to chronic kidney disease. Kidney Int. 2016;89:363-73.

44. Lima-Posada I, Portas-Cortés C, Pérez-Villalva R, et al. Gender differences in the acute kidney injury to chronic kidney disease transition. Sci Rep. 2017;7:12270.

45. Ishani A, Xue JL, Himmelfarb J, et al. Acute kidney injury increases risk of ESRD among elderly. J Am Soc Nephrol. 2009;20:223-8.

46. Mammen C, Al Abbas A, Skippen P, et al. Long-term risk of CKD in children surviving episodes of acute kidney injury in the intensive care unit: a prospective cohort study. Am J Kidney Dis. 2012;59:523-30

47. Bomback AS, Klemmer PJ. The incidence and implications of aldosterone breakthrough. Nat Clin Pract Nephrol. 2007:3:486-92.

48. Liu J, Kumar S, Dolzhenko E, et al. Molecular characterization of the transition from acute to chronic kidney injury following ischemia/reperfusion. JCl Insight. 2017;2: pii: 94716.

49. Basile DP, Bonventre JV, Mehta R, et al. Progression after AKI: understanding maladaptive repair processes to predict and identify therapeutic treatments. J Am Soc Nephrol. 2016;27:687-97.

50. Basile DP, Leonard EC, Tonade D, Friedrich JL, Goenka S. Distinct effects on long-term function of injured and contralateral kidneys following unilateral renal ischemia-reperfusion. Am J Physiol Renal Physiol. 2012;302:F625-35.

51. Basile DP, Friedrich JL, Spahic J, et al. Impaired endothelial proliferation and mesenchymal transition contribute to vascular rarefaction following acute kidney injury. Am J Physiol Renal Physiol. 2011:300:F721-33.

52. Basile DP. Rarefaction of peritubular capillaries following ischemic acute renal failure: a potential factor predisposing to progressive nephropathy. Curr Opin Nephrol Hypertens. 2004;13:1-7.

53. Bechtel W, McGoohan S, Zeisberg EM, et al. Methylation determines fibroblast activation and fibrogenesis in the kidney. Nat Med. 2010;16:544-50

54. Yang L, Besschetnova TY, Brooks CR, Shah JV, Bonventre JV. Epithelial cell cycle arrest in $\mathrm{G} 2 / \mathrm{M}$ mediates kidney fibrosis after injury. Nat Med. 2010;16:535-43, 1p following 143.

55. Barrera-Chimal J, Pérez-Villalva R, Rodríguez-Romo R, et al. Spironolactone prevents chronic kidney disease caused by ischemic acute kidney injury. Kidney Int. 2013;83:93-103.

56. Singh AP, Singh N, Singh Bedi PM. Estrogen attenuates renal IRI through PPAR- $\gamma$ agonism in rats. J Surg Res. 2016;203:324-30.
57. Bonventre JV. Maladaptive proximal tubule repair:cell cycle arrest. Nephron Clin Pract. 2014;127:61-4.

58. Chevalier RL. The proximal tubule is the primary target of injury and progression of kidney disease: role of the glomerulotubular junction. Am J Physiol Renal Physiol. 2016;311:F145-61.

59. Bramlage P, Swift SL, Thoenes M, et al. Non-steroidal mineralocorticoid receptor antagonism for the treatment of cardiovascular and renal disease. Eur J Heart Fail. 2016:18:28-37.

60. Venkatachalam MA, Weinberg JM, Kriz W, Bidani AK. Failed tubule recovery, AKI-CKD transition, and kidney disease progression. J Am Soc Nephrol. 2015:26:1765-76.

61. Grgic I, Campanholle G, Bijol V, et al. Targeted proximal tubule injury triggers interstitial fibrosis and glomerulosclerosis. Kidney Int. 2012;82:172-83

62. Basile DP, Donohoe D, Roethe K, Osborn JL. Renal ischemic injury results in permanent damage to peritubular capillaries and influences long-term function. Am J Physiol Renal Physiol. 2001:281:F887-99.

63. Bábícková J, Klinkhammer BM, Buhl EM, et al. Regardless of etiology, progressive renal disease causes ultrastructural and functional alterations of peritubular capillaries. Kidney Int. 2017:91:70-85

64. Hörbelt M, Lee SY, Mang HE, et al. Acute and chronic microvascular alterations in a mouse model of ischemic acute kidney injury. Am J Physiol Renal Physiol. 2007:293:F688-95.

65. Leonard EC, Friedrich JL, Basile DP. VEGF-121 preserves renal microvessel structure and ameliorates secondary renal disease following acute kidney injury. Am J Physiol Renal Physiol. 2008;295:F1648-57.

66. Nangaku M. Chronic hypoxia and tubulointerstitial injury: a final common pathway to end-stage renal failure. J Am Soc Nephrol. 2006:17:17-25.

67. Kong T, Eltzschig HK, Karhausen J, Colgan SP, Shelley CS. Leukocyte adhesion during hypoxia is mediated by HIF-1-dependent induction of beta2 integrin gene expression. Proc Nat Acad Sci U S A. 2004;101:10440-5.

68. Grgic I, Duffield JS, Humphreys BD. The origin of interstitial myofibroblasts in chronic kidney disease. Pediatr Nephrol. 2012:27:183-93.

69. Lin SL, Chang FC, Schrimpf C, et al. Targeting endotheliumpericyte cross talk by inhibiting VEGF receptor signaling attenuates kidney microvascular rarefaction and fibrosis. Am J Pathol. 2011;178:911-23.

70. Humphreys BD, Lin SL, Kobayashi A, et al. Fate tracing reveals the pericyte and not epithelial origin of myofibroblasts in kidney fibrosis Am J Pathol. 2010:176:85-97.

71. Lin SL, Kisseleva T, Brenner DA, Duffield JS. Pericytes and perivascular fibroblasts are the primary source of collagen-producing cells in obstructive fibrosis of the kidney. Am J Pathol. 2008:173:1617-27.

72. Chen YT, Chang FC, Wu CF, et al. Platelet-derived growth factor receptor signaling activates pericyte-myofibroblast transition in obstructive and post-ischemic kidney fibrosis. Kidney Int. 2011;80:1170-81.

73. Kramann R, Humphreys BD. Kidney pericytes: roles in regeneration and fibrosis. Semin Nephrol. 2014:34:374-83.

74. Schrimpf C, Xin C, Campanholle G, et al. Pericyte TIMP3 and ADAMTS1 modulate vascular stability after kidney injury. J Am Soc Nephrol. 2012;23:868-83.

75. Duffield JS. Cellular and molecular mechanisms in kidney fibrosis. J Clin Invest. 2014;124:2299-306.

76. Meng XM, Nikolic-Paterson DJ, Lan HY. Inflammatory processes in renal fibrosis. Nat Rev Nephrol. 2014:10:493-503.

77. Eriksen BO, Ingebretsen OC. The progression of chronic kidney disease: a 10-year population-based study of the effects of gender and age. Kidney Int. 2006;69:375-82

78. Barrera-Chimal J, Pérez-Villalva R, Ortega JA, et al. Mild ischemic injury leads to long-term alterations in the kidney: amelioration by spironolactone administration. Int J Biol Sci. 2015 11:892-900. 